Published in: International Journal of Behavioral Development (2007), 31, 514-525.

RUNNING HEAD: ETHNIC ATTITUDES, IDENTIFICATION AND SELF-ESTEEM

\title{
Children's implicit and explicit ethnic group attitudes, ethnic group identification, and self-esteem
}

\author{
Stephanie C. Davis \\ University of Surrey, $U K$ \\ Patrick J. Leman \\ Royal Holloway University of London, UK \\ Martyn Barrett \\ University of Surrey, $U K$
}

Corresponding author: Stephanie Davis, Department of Psychology, University of Surrey,

Guildford, Surrey GU2 7XH, UK. Email: s.c.davis@ surrey.ac.uk. Tel: +44 (0) 1483689436. Fax: +44 (0) 1483689553.

Acknowledgements: This research was supported by an Economic and Social Research Council (ESRC) Research Studentship Number PTA-030-2002-00900 to the first author. We would like to thank the staff, pupils and parents at the North London School for making us so welcome and for participating in this research.

Keywords: ethnic group, explicit attitudes, identification, implicit attitudes, self-esteem 


\title{
Children's implicit and explicit ethnic group attitudes, ethnic group identification, and self-esteem
}

\begin{abstract}
An increasing amount of research explores how children distinguish different aspects of ethnic group attitudes. However, little work has focused on how these aspects tie in with other social and psychological processes. In the present study, 112 black and white children aged 5-, 7- and 9-years completed tests of implicit and explicit ethnic group attitudes, racial and ethnic identification, and self-esteem. Whereas all children exhibited coherent identification with ethnicity defined in terms of family ancestry, only black children identified with ethnicity as defined by racial colour terms. There were no differences in black and white children's self-esteem. Children from both ethnic groups stereotyped only the black character. This stereotyping was stable with age. Positivity was greater towards the black than the white target on implicit and explicit tasks. Negativity towards the white target was evidenced on the implicit task. Positivity, but not stereotyping, was greater on the explicit task compared with the implicit task. Black but not white children's in-group identification was associated with implicit in-group stereotypes. Self-esteem was related to in- and out-group stereotyping and positivity for white but not black children. The implications of these results for social identity development theory and social identity theory are discussed.
\end{abstract}




\section{Children's implicit and explicit ethnic group attitudes, ethnic group identification, and self-esteem}

An increasing body of research into children's ethnic and racial group attitudes has built upon recent theorising regarding a dissociation between explicit and implicit attitudes (e.g. Baron \& Banaji, 2006; Rutland, Cameron, Milne \& McGeorge, 2005; Wilson, Lindsey $\&$ Schooler, 2000). Although there is much debate as to the potential meanings of such a dissociation in adults (see Devos \& Banaji, 2005; Fazio \& Olson, 2003), Nesdale (2001) notes that the majority of measures exploring the development of prejudice and ethnic group attitudes in children are explicit. As such, they may be contaminated by social desirability effects if children suppress socially unacceptable expressions of negative attitudes towards others. Nesdale suggests that implicit measures may, instead, provide more veridical assessments of a child's ethnic group attitudes. Although research has yet fully to elucidate the nature of a dissociation between implicit and explicit attitudes in children, it has been documented in a growing body of recent research (e.g. Baron \& Banaji, 2006; Davis \& Leman, 2004; Rutland et al., 2005). However, to date this research enterprise has not explored how implicit and explicit attitudes relate to children's ethnic identification and selfesteem.

The present study explored the links between implicitly and explicitly measured ethnic intergroup attitudes and both self-esteem and racial and ethnic in-group ${ }^{1}$ identification in a group of black British and white English children aged 5-9 years. Exploring the links between children's implicit and explicit attitudes, identification and self-esteem in both majority and minority group children is important because it constitutes a first step in charting the relationship between children's intergroup attitudes and other aspects of their

\footnotetext{
${ }^{1}$ Children's ethnic in-group was their ethnic group as subjectively defined by their parents to the school. The term 'ethnicity' denotes a system of shared beliefs, myths of ancestry and common cultural practices (Hutchinson \& Smith, 1996). Following Leach (2005), we use the terms 'racial' , 'race', 'black' and 'white' to denote pseudobiological categories that are made real by racism and racist practices.
} 
developing self-concept, and enables us to test the generality of existing theoretical claims which have been based primarily on data collected from majority group children only.

Previous work with children has indicated that a greater positivity for the ingroup compared with out-groups, and racial and ethnic stereotyping, are present from as young as 3 years of age (e.g. Clark \& Clark, 1947; Hirschfeld, 1993). Many studies have further revealed that in-group bias and the degree of stereotyping of both ingroups and out-groups increase until middle childhood, and then show a decline into early adolescence (see Aboud, 1988, for a review). In-group favouritism or preference has been found in relation to both artificially created groups (Yee \& Brown, 1992) and social groups (e.g. Bigler, 1995; Powlishta, 1995). In parallel with this greater positivity towards the in-group, some authors have also found negativity (or prejudice) towards ethnically or 'racially' different out-groups in early childhood (see Brown, 1995, for a discussion). Critically, however, much of this research has been conducted with majority (white) children in Western societies, and theorising in this field has commonly failed to consider challenging findings from work showing that minority children's attitude development can differ from that of majority (white) children (e.g. Bernal \& Knight, 1993; Ocampo, Knight \& Bernal, 1997; Spencer, 1984; Spencer \& Markstrom-Adams, 1990). Whereas this in-group positivity is almost consistently evidenced by majority group children, findings for minority group children are more mixed (see Spencer and Markstrom-Adams, 1990; Cross, 1991 for reviews).

In recent years, theorising about children's racial and ethnic attitudes has been dominated by cognitive developmental theory (CDT; Aboud, 1988) which suggests that children's ethnic and racial attitudes and prejudice are primarily the result of changes in cognitive development. More recently, however, the focus has shifted to a consideration of the influences of social motivational processes and other aspects of 
children's social selves. Drawing on theorising from Social Identity Theory (SIT; Tajfel, 1978; Tajfel \& Turner, 1979, 1986), social identity development theory (SIDT; Nesdale, 1999a, 2004) proposes that children's racial and ethnic attitudes develop through a sequence of four phases, and that the development is primarily driven by social motivational factors such as the pursuit of positive distinctiveness of the ingroup, self-esteem and a child's identification with the ethnic or racial in-group (Nesdale, Maass, Durkin, \& Griffiths, 2005b). In the first undifferentiated phase, before 2-3 years of age, racial and ethnic cues are not yet salient to young children. Thus, there is little understanding of either the self or of others in racial or ethnic terms. In the second phase, which starts at about 3 years, awareness of racial and ethnic cues begins to emerge, and children become able to identify and distinguish members of different groups. Crucially, at this second phase, self-identification as a member of a particular in-group also occurs. Thus, in line with SIT, SIDT suggests that ethnic identification is a precursor or prerequisite for ethnic preferences and biasing to occur. In the third phase, which begins at about 4 years of age, a focus on, and preference for, the in-group emerges as a consequence of in-group identification. During this phase, SIDT proposes that out-groups are not disliked or conceptualised in negative terms. Instead, the in-group is simply preferred over other groups. Drawing on parallels with SIT, this greater liking for the in-group is a consequence of the individual adult or child deriving self-esteem from a relatively more favourable view of the in-group, with which they identify, than of any out-group. However, this can be achieved by simply liking the in-group more, and disliking the out-group is not a requirement for self-esteem to be achieved in this manner. SIT further suggests that, rather than positivity of the in-group per se being the determining factor, it is the positive distinctiveness of the in-group (i.e. the greater positivity of the in-group over 
the out-group on dimensions appropriate to the situation) from which self-esteem is derived. SIDT suggests that it is only later, from around 7 years of age that prejudice is evidenced by some children. In this final phase, the focus shifts from the in-group to out-groups and instead of merely preferring the in-group the child begins to dislike out-groups. The probability of such prejudice appearing is hypothesised to increase as a function of several factors, including the child's level of in-group identification, and the extent to which the members of the in-group feel that their status or well-being is under threat from the out-group concerned (Nesdale, 2004; Nesdale, Durkin, Maass, \& Griffiths, 2005a). Although SIDT itself is silent on the issue of intergroup stereotyping, Nesdale (1999b) notes that childhood stereotyping occurs in a direction which supports in-group biasing and serves to render the in-group more favourable than the out-group. Thus, both SIT and SIDT suggest that both self-esteem and ingroup identification are highly influential factors influencing an individual's ethnic and racial biasing.

Although research with adults generally supports the key role for in-group identification and self-esteem in ethnic and racial biasing (see Oakes, Haslam \& Turner, 1994), there is less research demonstrating a clear link between these psychological processes in children. Indeed, some results suggest that the links may be mediated by peer victimisation (Verkuyten \& Thijs, 2001) and parental attitudes (Verkuyten, 2002), and that in-group identification may even not be necessary for explicitly measured in-group bias to occur in children (Bennett, Lyons, Sani, \& Barrett, 1998). Further, non-dominant research and theorising raises the question of whether the link between self-esteem and ethnic biasing in minority group children is adequately explained by SIT and SIDT. Spencer (1985) suggests that young black children may partition knowledge of their racial and ethnic groups from knowledge regarding the self, and whereas the former may influence children's racial and 
ethnic stereotyping, only this latter body of knowledge is used when assessing their selfesteem. Thus, Spencer (1985) suggests that self-esteem and racial and ethnic stereotyping and attitudes may not be related for black children. Research conducted with African American children supports this separation (Spencer, 1982, 1985; Alejandro-Wright, 1985; Semaj, 1980, 1985). Non-dominant researchers also note that the research indicating a link between self-esteem and ethnic biasing for young black children often involves the use of measures which confuse self-esteem and reference group orientation (i.e. ethnic identification) with one another (see Spencer, 1985; Cross, 1991).

The present study assessed both minority and majority group 5-, 7- and 9-year-old children's attitudes to their own in-group and to a salient out-group, their identification with their racial and ethnic in-groups, their self-esteem, and associations between these aspects of their psychological and social development. The research aimed to explore the postulated links between self-esteem, ethnic and racial identification and ethnic and racial biasing suggested by SIT and SIDT, and those suggested by less dominant research traditions. In line with recent research suggesting a dissociation between implicit and explicit assessments of children's social group attitudes (Baron \& Banaji, 2006; Davis \& Leman, 2004; Rutland et al., 2005), children's attitudes were assessed using not only explicit but also implicit measures. It was anticipated that there would be a dissociation between the two types of attitude, with the explicit attitudes revealing lower levels of prejudice towards the out-group than the implicit attitudes as a result of social desirability factors moderating the children's explicit expressions of prejudice (cf. Killen, Lee-Kim, McGlothlin \& Stangor, 2002; Rutland et al., 2005).

A key element of the present study was the exploration of the development of children's ethnic and racial identifications and their relationships to children's ethnic attitude development. The concept of in-group identification tends to be under-theorised by 
researchers in this field, with the in-group being treated as a relatively transparent and unproblematic category. However, racial and ethnic in-groups can usually be defined in terms of a multiplicity of different criteria including skin colour, religion, language, other cultural practices and familial country of origin (Hutchinson \& Smith, 1996; Hutnik, 1985; Modood, Berthoud, Lakey, Nazroo, Smith, Virdee, \& Beishon, 1997; Parekh, 2000). For this reason, the present study utilised two different measures of identification, one based on racial skin colour labels ('black' and 'white'), and the other on familial ancestry. The aim here was twofold: (i) to examine the development of children's subjective identifications with their own racial and ethnic group, and (ii) to examine the relationship between the strength of children's identifications with their own in-group and their intergroup attitudes. As we have seen, SIDT postulates that identification promotes a focus on the in-group which results in greater in-group positivity, and, after the age of 7, the emergence of prejudice towards outgroups is related to children's levels of identification with their own in-group. The present study tested these predictions.

As far as the three-way relationship between identification, intergroup attitudes and self-esteem is concerned, both SIT (Tajfel \& Turner, 1979) and SIDT (Nesdale et al., 2005b) implicate self-esteem as an important motivational factor in the construction of intergroup attitudes. The social identity perspective postulates that when individuals identify with a particular social group, they try to obtain a sense of positive self-esteem from that identity. Consequently, when those individuals construct representations of the in-group and of salient out-groups, dimensions of comparison are chosen which produce more favourable representations of the in-group than of out-groups, resulting in in-group favouritism or outgroup denigration or both. The positive distinctiveness which is ascribed to the in-group over the out-groups produces positive self-esteem. However, in order for these effects to occur, an individual must subjectively identify with that category. If identification is weak or absent, 
these effects may not occur. In addition, Aboud and Amato (2001) suggest that a connection between self-esteem and ethnic identification (such that children generalise their self-worth to the ethnic category with which they identify) may be a factor influencing children's positive evaluations of some groups and negative evaluations of others. In contrast, however, Spencer (1985) suggests that black children partition knowledge of the in-group from knowledge of the self, and use only self-based knowledge to assess self-esteem. This implies that selfesteem and ethnic biasing are unrelated in these children. Previous research with children indicates that the relationship between identification, intergroup attitudes and self-esteem may not be as straightforward as SIT implies, and Turner (1999) has also questioned whether SIT does indeed make such direct predictions about the relationship between identification, attitudes and self-esteem. In this study, we therefore examined the relationships between children's racial and ethnic in-group identification, attitudes and self-esteem.

Although implicit attitude research in children is a relatively new field, a number of authors have now utilised a version of the Implicit Association Test (IAT; Greenwald et al., 1998) to implicitly assess children's social group attitudes (e.g. Baron \& Banaji, 2006; Rutland et al., 2005). However, despite its success with children aged 6 years and older, it was judged that the increased modifications required for children below the age of 6 , and the variability in the motor control of 5-year-old children, meant that the IAT was not an optimal method to use in the present study, and a memory task was used instead. Fazio, Jackson, Dunton and Williams (1995) suggest that representations of ethnic groups and their associated traits are stored in memory and can be automatically activated, and memory biases are believed to reflect underlying social attitudes (Bartlett, 1932; Bigler \& Liben, 1993). Consequently, the memory task was used as an implicit assessment of children's attitudes. An additional advantage of the memory task was its similarity to the explicit task: in both tasks, children were asked to evaluate members of the in-group and the out-group in relation 
to the same set of specified stereotypical traits. However, in the explicit task, the children were aware that they were making judgements about black and white targets whereas in the implicit task they were not. Memory procedures have been widely used to assess ethnic attitudes in adults and children (e.g. Bigler and Liben, 1993; Dijksterhuis \& Van Knippenberg, 1995; Fyock \& Stangor, 1995; Nesdale, 1999b) and the present study built on this preceding body of research.

The present study therefore addressed the following three main questions: (i) Do black and white children in Britain show in-group biasing in relation to black and white targets? Does this biasing differ on implicit and explicit racial attitude assessments? (ii) Do black and white children with high identification with their own in-group show greater positivity towards the in-group, greater negativity towards the out-group, or attribute greater positive distinctiveness to the in-group, than minority and majority children who have low identification with their in-group? Does this relationship differ with implicit and explicit assessments? (iii) Do black and white children who show more positivity towards the ingroup and/or more negativity towards the out-group (or who attribute greater positive distinctiveness to the in-group) exhibit higher levels of self-esteem than children who show less positivity towards the in-group and/or less negativity towards the out-group (or who attribute lower positive distinctiveness to the in-group)? Does this relationship differ with implicit and explicit assessments?

\section{Method}

\section{Participants}

Children attended a co-educational multi-ethnic primary school in London, UK, comprising 680 pupils, $50 \%$ of whom were from ethnic minority group families (predominantly African-Caribbean or black African ancestry). Prior to the commencement of the research, both school and parental consent was obtained. The sample consisted of 112 
children (58 girls and 54 boys), 51 of whom were of white English ethnicity and therefore formed the 'white' group, and 61 of whom were black British and who therefore formed the 'black' group. There were 345 -year-olds $(M=5.35$ years, $S D=0.34), 417$-year-olds $(M=$ 7.26 years, $S D=0.39)$ and 37 9-year-olds $(M=9.24$ years, $S D=0.28)$.

Design

The design was a 2 (participant race: black, white) x 3 (age group: 5 years, 7 years, 9 years) between-subjects factorial design.

\section{Measures and Procedure}

The research was conducted in two phases. The first phase involved an assessment of children's implicit attitudes and levels of stereotyping using a story memory task (adapted from Nesdale, 1999b). Stereotypes used in the task were derived via a study exploring racial and ethnic stereotyping in the UK (Davis, Leman \& Smith, 2006). The children's implicit attitudes were always assessed first in order to avoid any possible contamination of the implicit data from the subsequent explicit task. The second phase involved three separate components: an assessment of children's explicit attitudes and levels of stereotyping using an attribution task (adapted from Doyle et al., 1988); an assessment of children's self-esteem using the Self-Perception Profile (Harter, 1985); and an assessment of children's levels of identification with their racial group as defined by their skin colour, and with their ethnic group as defined by their familial country of origin, using the Strength of Identification Scale (SoIS, adapted from Barrett, in press). The order of tasks in the second phase was randomised.

In the first phase, children were given a story memory task. The story concerned two characters, a black child and a white child, and was about a class trip to the zoo. There were two versions of the story, one featuring two boy characters and a second featuring two girl characters. During the course of the story, the black and white characters each exhibited eight activities which 
represented eight stereotypical traits (four stereotypical and four non-stereotypical) associated with being 'black' and 'white', respectively. These stereotypical traits were first obtained through an open-ended questionnaire with British adults from a variety of different ethnic groups, and their suitability was then verified through semi-structured focus group interviews with 35 British children aged between 5 and 9 years. For each of the characters, there were two positive and two negative traits of each stereotypical trait type. For the 'black' character the stereotypical traits were fast runner, good dancer, aggressive and loud, and the non-stereotypical traits were works hard, likes family, smelly and greedy. For the 'white' character the stereotypical traits were well-behaved, likes doing things alone/independently, thinks he's better than others and ignores others, and the non-stereotypical traits were polite, rich, stupid, and dirty. Two sets of colour illustrations (a male and a female version) depicting the characters engaged in each of the stereotypical trait activities were compiled to accompany the story. A five minute video of the story narrated by the first author and utilising the still colour illustrations was also produced.

Children in the two older age groups were divided into same sex groups; the boys always viewed the story featuring two boy characters, while the girls always viewed the story featuring two girl characters. The first author introduced the task by saying 'You are going to hear a story about two friends on a class trip to the zoo. I want you to listen really carefully because when the story is finished I'm going to ask you some questions to see how much you can remember'. The video of the story was then shown. After it had finished, each child was provided with an answer sheet containing 16 questions regarding who performed particular activities (relating to the stereotypical traits) in the story, and asked to complete this themselves. A picture depicting the head shots of each of the two children with their names written underneath was available to the children throughout. The 5-year-olds were instead seen individually in a quiet area near their classroom, where they viewed the same story on a portable DVD player. To test their recall of the stereotypical traits, these children were asked to point to the picture of the child who had 
performed the activity in the story. The picture consisted of the head shot of each of the two children with their names written underneath. The researcher recorded their responses. The number of stereotypical trait activities recalled and the number of non-stereotypical trait activities recalled committed by each character were recorded (range 0-4). The degree of stereotyping score was defined as (number of stereotypical trait activities recalled) minus (number of nonstereotypical trait activities recalled) for each character.

In the second phase, the children's explicit attitudes were assessed using the letter box task based on the Multi-response Racial Attitude (MRA) measure of Doyle et al. (1988). Four letter boxes $(16.5 \mathrm{~cm}$ cubes $)$ and sixteen cards $(7 \times 2.5 \mathrm{~cm})$ were used. Each box had an opening large enough to insert the cards. One of a new set of four drawn illustrations (a black boy and girl, and a white boy and girl) was stuck onto the front of each box. Children were presented with 16 cards, randomly ordered, carrying words describing of each of the 16 stereotypical traits. The cards were placed in front of the child on the table, and the first author introduced the task saying 'Here is a picture of a girl/boy and we're going to think about what s/he might be like. Now, just by looking at her/him, I want you to see what you think s/he might be like. We've got all these words that might describe her/him and you can use as many or as few as you would like. I want you to put any words that describe her/him into her box and leave any that don't on the table, ok?' The boxes were presented one at a time, in counterbalanced order; the boys were given the two boy boxes in turn, while the girls were instead given the two girl boxes. For the 5- and 7-year-olds, the experimenter read each card in turn; the 9-year-olds read the cards themselves. The number of stereotypical traits and the number of non-stereotypical traits assigned to each character were calculated (range: 0-4). Degree of stereotyping was calculated as (number of stereotypical traits assigned) minus (number of non-stereotypical traits assigned) to each character.

Items from the social acceptance and global self-worth sub-scales of the SelfPerception Profile (Harter, 1985) were put together to comprise the self-esteem task. The six 
items from each of these subscales were alternated in a twelve item questionnaire. Children were told that they were going to think about what they might be like and that they would go through some questions and they should choose the sentence that described them the best. Children were told that there were no right or wrong answers and that everyone chooses different sentences as everyone is different, so they should think what described them the best. For each item, children were required to choose one of a pair of sentences which most described them (e.g. Global Self-worth item: Some kids are often unhappy with themselves but other kids are pretty pleased with themselves, which one is most like you?'; Social Acceptance Item: Some kids find it hard to make friends, but other kids find it's pretty easy to make friends, which one is most like you?') Children were then required to say whether the chosen sentence was 'sort of true' or 'really true' for them. Children completed a practice question to familiarise themselves with the task followed by the twelve item questionnaire. Children scored 1-4 for each item $(1=$ low esteem and $4=$ high esteem $)$. A mean score for each subscale (range 1-4) was then calculated based on the relevant item scores.

Finally, the Strength of Identification Scale (SoIS; adapted from Barrett, in press) was used to assess children's identification with their racial group as defined by their skin colour label (Colour) and their ethnic group as defined by their familial country of origin (Country). The questionnaire consisted of six questions which asked about children's degree of identification, affect (positive and negative), internalisation, importance, and pride. Some questions were accompanied by cards depicting smiley faces in a 5 point Likert scale, and others were accompanied by printed responses. Questions were presented in a randomised order. The questions were: 1) Which one of these do you think best describes you? Are you extremely Angolan, very Angolan, quite Angolan, a little bit Angolan or not at all Angolan; 2) Which face shows how you feel about being Angolan? Very happy, quite happy, neither happy or sad, quite sad, very sad; 3) Which face shows how you would feel if someone said 
something bad about Angolan people? Very happy, quite happy, neither happy or sad, quite sad, very sad; 4)Which face shows how you would feel if someone said something bad about Angolan people? Very happy, quite happy, neither happy or sad, quite sad, very sad; 5) How important is it to you that you are Angolan? Is it not at all important, not very important, quite important, very important, or extremely important?; and 6) which card shows how proud you are of being Angolan? Are you Not at all proud, a little bit proud, quite proud, very proud, extremely proud?). Children were told that they were going to continue thinking about what they were like and that some people might describe them as being from a particular ethnic background or national origin but the researcher was interested in what they themselves thought about that. The researcher then went through each question with the child using the response cards on which the possible answers were written to facilitate the task. The order of questioning the children about their Colour identification and Country identification was counterbalanced across the children, and the order of administering the six questions within each block of questions was randomised. Children scored 1-5 for each item $(1=$ low identification and $5=$ high identification). A mean score (range 1-5) was then calculated for Colour and Country from the relevant item scores.

\section{Results}

The data from the implicit and explicit tasks were analysed using 2 (participant race: black vs. white) x 3 (age group: 5 vs. 7 vs. 9) x 2 (target race: black vs. white) mixed ANOVAs with independent groups on the first two factors and repeated measures on the third factor.

\section{Implicit task}

Degree of Implicit Stereotyping. Following Dijksterhuis and Van Knippenberg (1995) stereotyping was present if children recalled significantly more stereotypical than nonstereotypical trait information regarding the characters. The degree of stereotyping was 
operationally defined as: (the number of stereotypical traits recalled) minus (the number of non-stereotypical traits recalled). The degree of stereotyping of the black and the white target characters in the story was analysed using the mixed ANOVA. This revealed only one significant effect, a main effect of target race $\left(F(1,96)=7.81, p<0.01, \eta_{\mathrm{p}}{ }^{2}=0.08\right)$, with there being a higher degree of stereotyping of the black character $(M=0.29, S D=0.91)$ than of the white character $(M=-0.18, S D=1.27)$ overall. No other effects were significant, and it is notable that there were no significant effects involving age group. Two one-sample t-tests further revealed that the mean score for the black character (0.29) was significantly higher than 0 (a score of 0 represents no stereotyping) $(t(101)=3.27, p<0.001)$ but that the mean score for the white character $(-0.18)$ was not significantly different from $0(t(101)=1.48, \mathrm{~ns})$. Thus, only the black character was stereotyped on the implicit task.

Positivity of Implicit Attitudes. The overall positivity of the children's attitudes towards the two story characters was calculated by subtracting the number of negative traits recalled for each of the two characters from the number of positive traits recalled for that character. The mixed ANOVA revealed a significant main effect of target race $(F(1,106)=$ $\left.30.44, p<0.001, \eta_{\mathrm{p}}^{2}=0.22\right)$, in which the black target $(M=1.06, S D=2.00)$ had higher positivity scores overall than the white target $(M=-1.05, S D=2.01)$. However, this main effect was qualified by a significant target race $\mathrm{x}$ participant race interaction effect $(F(1,106)$ $\left.=4.64, p<0.05, \eta_{\mathrm{p}}^{2}=0.04\right)$. Post hoc $\mathrm{t}$-tests revealed that the black children $(M=1.44, S D=$ 2.07) had significantly higher positivity scores towards the black story character than the white children $(M=0.61, S D=1.83)$, while the white children $(M=-0.63, S D=1.83)$ had significantly higher positivity scores towards the white story character than the black children $(M=-1.41, S D=2.09)$ (these means were less than zero, indicating negativity rather than less positivity towards this group). One-sample t-tests $(p<0.05)$ revealed that all four of these means were significantly different from 0 (respectively: $t(60)=5.44, p<0.001 ; t(50)=2.37$, 
$p<0.05 ; t(50)=2.45, p<0.05 ; t(60)=5.26, p<0.001)$. Thus, both the black and the white children were positive overall towards the black character, and negative overall towards the white character, but the black and white children differed in their responses depending on whether the target belonged to their in-group or to the out-group and they differed from each other in this regard. Black children were positive towards the in-group character and negative towards the out-group target, whereas white children were negative towards the in-group character and positive towards the out-group character. No other effects were significant, and once again it is noteworthy that there were no significant effects involving age group.

\section{Explicit task}

Degree of Explicit Stereotyping. Analogous analyses were conducted on the scores derived from the explicit task. The degree of stereotyping on the explicit task was operationally defined as: (the number of stereotypical traits attributed to a particular target) minus (the number of non-stereotypical traits attributed to that target). These scores were also analysed using a mixed ANOVA, which only revealed one significant effect, a main effect of participant race $\left(F(1,98)=4.17, p<0.05, \eta_{\mathrm{p}}{ }^{2}=0.04\right)$, in which the black children stereotyped both the black target $(M=0.38, S D=0.85)$ and the white target $(M=0.29, S D=$ 1.21) significantly more than the white children stereotyped the black target $(M=0.04, S D=$ $1.19)$ and the white target $(M=-0.02, S D=1.00)$ respectively. Again, it is notable that there were no significant effects involving age group. One-sample t-tests revealed that the white children's scores were not significantly different from 0 , but that the black children's degree of stereotyping of the black target was significantly higher than $0(t(57)=3.38, p<0.001)$ and the black children's degree of stereotyping of the white target was marginally higher than $0(t(57)=1.84, p=0.07)$.

Positivity of Explicit Attitudes. The positivity of the children's attitudes towards a particular target was calculated by subtracting the number of negative traits attributed to that 
target from the number of positive traits attributed to that target. The mixed ANOVA revealed a significant main effect of age group $\left(F(2,98)=6.24, p<0.005, \eta_{\mathrm{p}}{ }^{2}=0.11\right)$ and a marginally significant effect of target race $\left(F(1,98)=3.42, p=0.07, \eta_{\mathrm{p}}{ }^{2}=0.03\right)$. No other effects were significant. The relevant means are shown in Table 1. As this table reveals, levels of positivity tended to be higher towards the black target than the white target overall, irrespective of the children's own race. Post hoc Student-Newman-Keuls analysis revealed that the 7-year-olds' scores were significantly higher than both the 5-year-olds' and the 9year-olds' scores, while the 5-year-olds' and the 9-year-olds' scores did not differ significantly from each other. It is noteworthy that the children's explicit attitudes to both the black and the white targets were positive at all three ages, although one-sample t-tests (reported in Table 1) revealed that the 9-year-old's attitudes specifically towards the white target were in fact neutral rather than positive overall.

\section{Strength of identification scores for Colour and Country}

The SoIS Country measure was reliable for both black children (Cronbach alpha $=$ $0.61)$ and white children (Cronbach alpha $=0.67)$. However, the SoIS Colour measure was only reliable for black children $($ Cronbach alpha $=0.67)$, not for white children (Cronbach alpha $=0.41$ ). As a consequence of this low reliability of the Colour measure for the white children, this measure was only used further in analyses of the black children's data.

In order to explore the black children's strength of identification scores, a 3 (age group) x 2 (identity type: Country vs. Colour) mixed ANOVA with independent groups on the first factor and repeated measures on the second factor was conducted. This revealed a significant effect of age group $\left(F(2,52)=3.49, p<0.05, \eta_{\mathrm{p}}{ }^{2}=0.12\right)$, but no significant effect of identity type and no significant interaction. Post hoc Student-Newman-Keuls analysis revealed that the 5-year-olds had lower levels of identification overall $(M=3.71)$ than the 9year-olds $(M=4.19)$, but that the 7-year-olds $(M=3.90)$ did not differ significantly from 
either of the other two groups. The strength of the white children's Country identification was analysed using a one-way ANOVA with age group as the independent variable, which revealed no significant effects of age group on the children's levels of identification (overall $M=4.10, S D=0.71)$.

\section{Self-esteem}

The global self-worth subscale was reliable for both black children (Cronbach alpha $=$ $0.60)$ and white children $($ Cronbach alpha $=0.77)$. The social acceptance scale was reliable for white children $($ Cronbach alpha $=0.69)$, and was moderately reliable for black children $($ Cronbach alpha $=0.58)$.

The children's self-esteem scores were analysed using a 2 (participant race: black vs. white) x 3 (age group: 5 vs. 7 vs. 9) x 2 (self-esteem type: social acceptance vs. global selfworth) mixed ANOVA with independent groups on the first two factors and repeated measures on the third factor. This revealed a significant main effect of self-esteem type $(F(1$, $\left.97)=19.95, p<0.001, \eta_{\mathrm{p}}{ }^{2}=0.17\right)$. Children's global self-worth scores were higher than their social acceptance scores (global self-worth $M=3.17, S D=0.53$; social acceptance $M=2.89$, $S D=0.54)$. No other effects were significant.

\section{Implicit vs. explicit tasks}

Analyses were also conducted to examine whether the children's scores on the implicit and explicit tasks were significantly different. A 2 (implicit vs. explicit) x 2 (participant race: black vs. white) x 3 (age group: 5 vs. 7 vs. 9) mixed ANOVA with repeated measures on the first factor and independent groups on the second and third factors revealed no significant effects involving the implicit vs. explicit factor on the degree of stereotyping of black targets. However, a second mixed ANOVA, conducted on the degree of stereotyping of the white targets, did reveal a significant main effect of the implicit vs. explicit factor $\left(F(1,89)=5.73, p<0.05, \eta_{\mathrm{p}}{ }^{2}=0.06\right)$ which, 
however, was qualified by an interaction between the implicit-explicit factor and the participants' own race $\left(F(1,89)=5.10, p<0.05, \eta_{\mathrm{p}}^{2}=0.05\right)$. Post hoc paired-sample t-tests revealed that there was no significant difference between the implicit $(M=-0.05, S D=1.17)$ and explicit $(M=-0.02$, $S D=1.02$ ) scores of the white children, but that there was a significant difference between the implicit $(M=-0.34, S D=1.36)$ and explicit $(M=0.47, S D=1.08)$ scores of the black children $(t(52)=3.43, p<0.001)$. Thus, there was a dissociation between the degree of stereotyping of the white targets in the implicit vs. the explicit tasks in the case of the black children (with the degree of stereotyping being higher on the explicit task), but not in the case of the white children.

A third mixed ANOVA analysing the overall positivity towards the black targets revealed a significant main effect of the implicit vs. explicit factor $(F(1,98)=19.71, p<$ $\left.0.001, \eta_{\mathrm{p}}{ }^{2}=0.17\right)$, but no significant interaction effects involving this factor. The children as a whole were more positive towards the black target on the explicit $(M=2.68, S D=3.44)$ than on the implicit $(M=1.09, S D=1.96)$ task. A fourth mixed ANOVA revealed that overall positivity towards the white targets also showed a similar significant main effect of the implicit vs. explicit factor $\left(F(1,98)=44.06, p<0.001, \eta_{\mathrm{p}}{ }^{2}=0.31\right)$ and no significant interactions involving this factor. Once again, the children as a whole were more positive towards the white target on the explicit $(M=1.63, S D=3.75)$ than on the implicit $(M=-1.11$, $S D=1.95)$ task. Thus, in the case of the children's overall levels of positivity towards both the black and the white targets, there was a clear dissociation between the children's implicitly and explicitly assessed attitudes: the children were consistently more positive towards targets on the explicit than on the implicit task. However, the raw means indicate that the children were positive towards the white character on the explicit task, and were negative on the implicit task (not just less positive). 
The relationships between the variables

Before running correlations between the different dependent variables, two new scores were derived in order to permit exhaustive testing of the predictions made by SIT concerning the relationship between intergroup attitudes, the strength of identification with the ingroup and self-esteem. These two new scores both represented measures of the positive distinctiveness of the in-group over the out-group. An implicit positive distinctiveness score was operationally defined as (the overall positivity of the in-group on the implicit task) minus (the overall positivity of the out-group on the implicit task), while an explicit positive distinctiveness score was operationally defined as (the overall positivity of the in-group on the explicit task) minus (the overall positivity of the out-group on the explicit task).

Pearson partial correlation coefficients, with age partialled out, were then conducted between the various implicit and explicit attitude measures and the strength of identification and self-esteem measures. The correlations were conducted separately for the black children (see Table 2) and for the white children (see Table 3), as the in-group and the out-group differed between these two groups of children.

Table 2 reveals that, for the black children, the Country and Colour identification scores were correlated with each other, and both identification scores were related to the children's global self-worth. In addition, the extent to which the black children explicitly stereotyped the black target was correlated both with their strength of identification with their familial Country of origin, and with their global self-worth. No other correlations were significant for the black children. It is noteworthy that neither of the two positive distinctiveness scores was correlated either with the children's strength of identification or with their self-esteem, and none of the measures of the children's attitudes to the white outgroup were related to the children's strength of identification with their own in-group either. Because SIDT specifically postulates that one of the conditions required for the development 
of negative prejudice towards out-groups after the age of 7 is strong identification with the ingroup, the same correlational analyses were also performed on the three age groups separately. These analyses revealed that amongst both the 5-year-olds and the 9-year-olds, there were no significant correlations between either of the two identification measures and any of the out-group attitude measures. At the age of 7, however, the strength of the black children's Country and Colour identifications were both negatively correlated with their implicit positivity towards the white target (Country $r=-0.66, p<0.01$; Colour $r=-0.60, p<$ 0.05), and the strength of their Colour identification was positively correlated with their degree of implicit stereotyping of the white target $(r=0.55, p<0.05)$.

Table 3 shows the correlations for the white children. Interestingly, there were numerous correlations between the white children's intergroup attitudes and their global selfworth. Most notably, there were positive correlations between the children's global selfworth and the positive distinctiveness of the in-group measured both implicitly and explicitly, as SIT would predict. In addition, there were significant negative correlations between the children's global self-worth and the levels of both their implicit and explicit positivity towards the black targets, and a significant positive correlation between their global selfworth and their implicit positivity towards the white target (all of which would have fed into the correlations with the positive distinctiveness of the in-group). The two final significant correlations, however, run counter to prediction: the higher the white children's global selfworth, the lower their degree of implicit stereotyping of the black target; and the higher the children's social acceptance self-esteem, the more they implicitly stereotyped the white target. When these various correlations were repeated on each age group individually in order to test the SIDT prediction concerning a relationship between identification and the emergence of negative prejudice after the age of 7, it was found that the white children's 
strength of Country identification was not significantly correlated with any of the variables which measured the children's out-group attitudes, at all three ages.

Implicit Task - Methodological Check

In order to examine whether there was a relationship between the position of a trait in the story and its recall, mean scores and standard deviations for children's recall of each item by position were calculated. Scores are illustrated in Table 4. Spearman's correlation revealed that the mean score for each item was not correlated with trait story position (black children: Spearman rho = -.16, ns.; white children: Spearman rho $=.01$, ns; All children: Spearman rho $=-.11, \mathrm{~ns})$

\section{Discussion}

The present study charted the relationship between children's intergroup attitudes and other aspects of their developing self-concept, and tested the generality of existing theoretical claims which have been based primarily on data collected from majority group children. Our first question asked whether black and white children would exhibit in-group biasing and intergroup stereotyping and whether this would differ on implicit and explicit measures. Overall, results revealed that whereas black children showed greater positivity for the ingroup target on both implicit and explicit assessments, white children showed greater positivity for the black out-group target than the white in-group target on both implicit and explicit assessments. Further, whereas children exhibited stereotyping of the black targets on both implicit and explicit assessments, there was not a significant degree of stereotyping of the white targets on either assessment. There were some significant differences between results from the two attitude assessments. In relation to children's stereotyping of black targets, there was no dissociation between findings from the two procedures, and the degree of stereotyping remained stable with age. In contrast, there was a dissociation between black 
children's (but not white children's) degree of stereotyping of the white target on the implicit and explicit tasks. An assessment of overall positivity revealed that both black and white children were more positive towards the white and the black targets on the explicit than the implicit task. Within this, black children were more positive regarding the in-group (black) target on both the implicit and explicit tasks. This greater in-group positivity was not evident for the white children. Instead, both groups demonstrated overall negativity towards the white character on the implicit task and positivity on the explicit task.

Our findings revealed no age differences in stereotyping, which supports SIDT's assertion that social motivational factors and not age-related cognitive development is a driver for children's ethnic attitude development. However, the present results pose difficulties for SIDT accounts, because this stereotyping focussed on one ethnic group (the black character) only. SIDT would anticipate that basic in-group and out-group processes would apply to all ethnic groups (that is, to both the black and white characters in the present study). This unexpected pattern of stereotyping for different ethnic groups occurred on both the explicit and implicit task. If social desirability was an ingredient in children's responses, this would be visible only on explicit measures (see Nesdale, 2001). Further research is needed to explore these intriguing results further and to establish whether broader social norms or aspects of children's peer cultures may account for the results here.

Children showed more positivity towards each target character on the explicit than the implicit task. Interestingly, both groups were more positive about the black than the white target on both assessments, and both groups showed negativity towards the white character on the implicit task. Further, whereas black children showed greater in- versus out-group positivity, the same was not true for white children. Moreover, although black children showed implicit negative bias towards white out-group targets, white children did not show implicit bias towards black out-group targets. This study produced more pronounced positive 
in-group and less positive out-group biasing amongst black children than has been found in previous studies in the UK (see Brown, 1995). The presence of a black experimenter in this study raises the question of the effect of in-group experimenters on implicit biasing. Lowery, Hardin, \& Sinclair (2001) found that white adults showed higher implicit biasing against black targets in the presence of white (in-group) experimenter as opposed to a black (out-group) experimenter. Together, these results are suggestive of a picture in which implicit out-group biasing is facilitated by the presence of an in-group experimenter. Further, these results contrast with research conducted by white experimenters which shows high levels of implicit in-group biasing amongst white children (Baron \& Banaji, 2006; Nesdale, 1999b). In line with Lowery et al. (2001), and the findings for black children reported here, the question is raised with regards to the potential facilitating effect of a white in-group experimenter on white children's implicit in-group biasing in these other studies. Together with findings of Lowery et al. (2001), the research conducted here suggests that social tuning occurs in relation to implicit biasing in both ethnic minority and majority group adults and children. A comparison between the present data which show clear in-group biasing in black children in the presence of a black experimenter, other findings showing ambivalent in-group attitudes in black children in the presence of a white experimenter (e.g. Aboud \& Doyle, 1995; Horowitz \& Horowitz, 1938), and research showing clear in-group biasing in white children in the presence of a white experimenter (e.g. Baron \& Banaji, 2006; Rutland et al., 2005), points to social tuning whereby the presence of an in-group experimenter acts to facilitate implicit expressions of in-group biasing.

This finding of in-group biasing amongst black children is also of note, given the widespread negative attitudes towards black individuals which often prevail in the media, political and civil institutions and in numerous activity domains within the UK which may be transmitted to children (Modood et al., 1997; Parekh, 2000). However, these results strike a chord with some other recent observations of children and adolescents in the UK which 
suggest that British children from all ethnic groups (including the white majority group) currently place a high value on 'black culture' (e.g., Ali, 2003; Back, 1996). Thus, this 'value' of black culture may dominate in some aspects of children's current peer environment, the area from which our children came at least.

Notwithstanding this, the greater in-group positivity on the part of the black children is in line with the ethnic preference phase predicted by SIDT (Nesdale, 2004). However, ethnic preference was evident in the ethnic minority group and not in majority group children. By contrast, on the implicit task, the white children actually showed greater positivity or preference towards the out-group, which is counter to the predictions of SIDT. Although one explanation for these results may relate to the fact that the present study was conducted by a black experimenter, an equally intriguing possibility is that this finding represents an extrapolation of the value placed on black culture noted earlier (e.g. Back, 1996) to black individuals who are consequently viewed in a more positive light. The finding underscores that further research is needed to tease apart the involvement of race-ofexperimenter effects in studies of ethnic understanding and to help to clarify how far any context effects influence children's attitudes and ethnic group preferences.

Secondly, we asked whether minority and majority group children with high identification with their own in-group would show greater positivity towards the in-group, greater negativity towards the out-group, or attribute greater positive distinctiveness to the ingroup, than those with low identification. Overall, black children identified with both their race as defined by Colour and their ethnicity as defined by Country of familial ancestry, whereas the white children identified only with their ethnicity as defined by Country of familial ancestry. High identification with Country-defined in-group was related to higher levels of explicit stereotyping of the in-group only for black children. White children's in- 
group identification was unrelated to either assessment of their attitudes towards black and white targets.

Black children's clear identification with both their Colour-defined and Countrydefined in-groups accords with research demonstrating that both adults and children from minority backgrounds, use multiple characteristics to define themselves (Fine \& Bowers, 1984; Hutnik, 1985; Mahan, 1976; Modood et al., 1997; Parekh, 2000). However, the absence of a relationship between these children's in-group identification and their in-group positivity stands in contrast to SIDT's suggestion that identification both focuses children on the in-group and gives rise to in-group positivity (Nesdale, 2004). Instead, black children's in-group identification related to their stereotyping of in-group targets. This suggests that the effect of in-group identification was to unify perception of the in-group, for minority group children at least.

The absence of a coherent identification with the Colour-defined in-group for white children raises the question of whether racial identities may be seen as a property of minorities, rather than of the dominant group, by dominant group members. Thus 'whiteness' may not be a factor that is particularly relevant for either white children's or white adults' self-definitions (Jensen, 2005). This idea would fit with proposals which have recently been made concerning normativity, according to which majority individuals view only the members of minority groups, and not members of the majority group, as 'bearers' of racial and/or ethnic characteristics (Pratto, Hegarty \& Korchmaros, in press; Pratto, Korchmaros \& Hegarty, in press). Despite demonstrating identification with Country-defined ethnicity, white children's in-group identification was not related to attitudes towards black and white children. This accords with findings demonstrating the absence of a relationship between ingroup identification and national group biasing evidenced amongst British children (Bennett et al., 1998). 
Our third question asked whether ethnic minority and majority group children who show more positivity towards the in-group and/or more negativity towards the out-group (or who attribute greater positive distinctiveness to the in-group) exhibit higher levels of selfesteem than other children. The present analysis revealed no relations between self-esteem and in- or out-group positivity for the black children. However, there were a number of such relations for the white children. White children's global self-esteem was negatively associated with both outgroup positivity and outgroup stereotyping but was positively associated with in-group positivity (and, hence, positive distinctiveness). Further, these correlations were in the direction suggested by SIT. That is, high self-esteem for white children was associated with greater in-group positive distinctiveness and in-group positivity, and with lower out-group positivity.

Results from this study therefore support the social identity theories' focus on selfesteem as a motivating factor driving in-group biasing for white but not black children. Instead, findings for black children accord with theorising by Spencer $(1985,1988)$ regarding a separation between young black children's group and self-knowledge (so-called ‘cultural egocentrism') which facilitates high self-esteem. Indeed, self-esteem scores for these children were comparable with those found for white children. It may be the case that black children do partition 'self' from 'group' and rely on sources related to 'self' rather than 'group' to develop their self-esteem (e.g., personal attributes, African-centred world views: see Cross, 1981). Thus, it may be the case that mechanisms involving self-esteem put forward by existing theories of ethnic attitude development may need to be adapted to account for the development of ethnic minority group children. While it may present a challenge to SIDT, in one sense these findings are not particularly surprising, given the lower status, disadvantage, negativity and discrimination experienced by the black racial group in the UK (Dalal, 2002; Modood et al., 1997; Parekh, 2000). Whereas some measure of self-advantage and positivity 
can be gained from an evaluation of the real-world situation for one's group for white individuals, the same is not true for black individuals.

The present research revealed variations in the relationships between self-esteem, ingroup identification and implicit and explicit ethnic group attitudes and stereotyping in young black and white British children. In particular there were different patterns of relationships for black and white children. There was a notable absence of age-related trends for children's stereotyping of and overall positivity towards black and white targets. Identification with the ethnic in-group differed according to participant ethnic group. The complex nature of the links between children's ethnic in-group identification, self-esteem and ethnic group attitudes and stereotyping points to the need for more studies considering the relationship between broader social and psychological factors and ethnic group attitudes in children. Such studies will not only help us to understand the determinants and consequences of children's ethnic group attitudes and preferences, but will also help to refine theoretical formulations in this area. 


\section{References}

Aboud, F. E. (1988). Children and Prejudice. New York: Blackwell.

Aboud, F. \& Amato, M. (2001). Developmental and socialization influences on intergroup bias. In R. Brown \& S.L. Gaertner (Eds.), Blackwell Handbook of Social Psychology: Intergroup Processes (pp. 65-85). Oxford: Blackwell.

Aboud, F. E., \& Doyle, A. B. (1995). Development of in-group pride in Black Canadians. Journal of Cross-Cultural Psychology, 26, 243-254.

Asher, S. R. \& Allen, V. L. (1969). Racial preference and social comparison processes. Journal of Social Issues, 25, 157-67.

Alejandro-Wright, M. N. (1985) The child's conception of racial classification: A sociocogntiive developmental model. In M. B. Spencer, G. K. Brookins \& W. R. Allen (Eds.) Beginnings: The social and affective development of Black children (pp. 185200). Hillsdale, N. J. Erlbaum.

Ali, S. (2003). Mixed-Race, Post-Race: New Ethnicities and Cultural Practices. Oxford: Berg.

Back, L. (1996). New Ethnicities and Urban Culture: Racisms and Multiculture in Young Lives. London: UCL Press.

Baron, A. S. \& Banaji, M. R. (2006). The development of implicit attitudes: Evidence of race evaluations from ages 6 and 10 and Adulthood. Psychological Science, 17, 53-58.

Barrett, M. (in press). Children's Knowledge, Beliefs and Feelings about Nations and National Groups. Hove: Psychology Press.

Bartlett, F. C. (1932). Remembering. Cambridge: Cambridge University Press.

Bennett, M., Lyons, E., Sani, F. \& Barrett, M. (1998). Children's subjective identification with the group and ingroup favoritism. Developmental Psychology, 34, 902-909. 
Bernal, M.E. \& Knight, G.P. (Eds.) (1993). Ethnic Identity: Formation and Transmission among Hispanics and other Minorities. Albany, NY: State University of New York Press.

Bigler, R. S. (1995). The role of classification skill in moderating environmental influences on children's gender stereotyping: A study of the functional use of gender in the classroom. Child Development, 66, 1072-1087.

Bigler R. S., \& Liben L. S. (1993). A cognitive-developmental approach to racial stereotyping and reconstructive memory in Euro-American children. Child Development, 64, 15071518.

Brown, R. (1995). Prejudice: Its Social Psychology. Oxford: Blackwell

Clark, K. B., \& Clark, M. P. (1947). Racial identification and preference in Negro children. In T. M. Newcomb \& E. L. Hartley (Eds.), Readings in Social Psychology (pp. 169178). New York: Holt.

Connolly, P. (1998). Racism, Gender Identities and Young Children. London: Routledge.

Cross, W. (1981). Black Identity: Rediscovering the distinction between personal identity and references group orientation. Paper presented at Society for Research on Child Development Study Group, Emory University, Atlanta.

Cross, W. E. (1991). Shades of Black. Philadelphia: Temple University Press.

Dalal, F. (2002). Race, Colour and the Processes of Racialisation: New Perspectives from Group Analysis, Psychoanalysis and Sociology. East Susses: Brunner-Routledge.

Davey, A. G. (1983). Learning to be Prejudiced: Growing up in Multi-Ethnic Britain. London: Edward Arnold.

Davis, S. C., \& Leman, P. J. (2004). Children's implicit and explicit ethnic group attitudes. Poster presented at the $18^{\text {th }}$ Biennial meeting of the International Society for the Study of Behavioural Development (ISSBD), July 11-15, Ghent, Belgium. 
Davis, S. C., Leman, P. J., \& Smith, P.K. (2006). Explicit and Implicit Ethnic Group Attitudes and Stereotypes in Middle Childhood. Manuscript submitted for publication.

Devos, T. \& Banaji, M.R. (2005). American = White? Journal of Personality and Social Psychology, 88, 447-466.

Dijksterhuis, A. P., \& Van Knippenberg, A. D. (1995). Memory for stereotype-consistent and stereotype inconsistent information as a function of processing pace. European Journal of Social Psychology, 25, 689-693.

Doyle, A. B., Beaudet, J., \& Aboud, F. E. (1988). Developmental patterns in the flexibility of children's ethnic attitudes. Journal of Cross-Cultural Psychology, 19, 3-18.

Fazio, R.H., Jackson, J.R., Dunton, B.C., \& Williams, C.J. (1995). Variability in automatic activation as an unobtrusive measure of racial attitudes: a bona fide pipeline? Journal of Personality and Social Psychology, 69, 1013-27

Fazio, R. H., \& Olson, M. A. (2003). Implicit measures in social cognition research: Their meaning and use. Annual Review of Psychology, 54, 297-327.

Fine, M., \& Bowers, C. (1984) Racial Self-identification: The effects of history and gender. Journal of Applied Social Psychology, 14, 136-146.

Fyock, J., \& Stangor, C. (1995). The role of memory biases in stereotype maintenance. British Journal of Social Psychology, 33, 331- 343.

Greenwald, A.G., McGhee, D.E., \& Schwartz, J.K.L. (1998). Measuring individual difference in implicit cognition: The implicit association test. Journal of Personality and Social Psychology, 74, 1464-1480.

Harter, S. (1985). Manual for the Self-Perception Profile for Children. Denver: University of Denver.

Hirschfeld, L. A. (1993). Discovering social difference: The role of appearance in the development of racial awareness. Cognitive Psychology, 25, 317-350. 
Holmes, R. M. (1995). How Young Children Perceive Race. Sage Series on Race and Ethnic Relations, 12.

Horowitz, E.L., \& Horowitz, R. E. (1938). Development of Social Attitudes in children. Sociometry, 1, 301-338.

Hutchinson, J. \& Smith, A.D. (1996). Introduction. In J. Hutchinson \& A.D. Smith (Eds.), Ethnicity (pp. 1-14). Oxford: Oxford University Press.

Hutnik, N. (1985) Aspects of identify in a multi-ethnic society. New Community, 12, 298309.

Jensen, R. (2005). The Heart of Whiteness: Confronting Race, Racism and White Privilege. San Francisco, CA: City Lights

Katz, P. A. (1976). The acquisition of racial attitudes in children. In P.A. Katz (Ed.), Towards the Elimination of Racism (pp. 125-154). New York: Pergamon Press.

Killen, M., Lee-Kim, J., McGlothlin, H. \& Stangor, C. (2002). How children and adolescents evaluate gender and racial exclusion. Monographs of the Society for Research in Child Development, Serial no. 271, Vol. 67, No. 4.

Leach, C. W. (2005). Against the Notion of a 'New Racism'. Journal of Community \& Applied Social Psychology, 15, 432-445.

Lowery, B. S., Hardin, C. D., \& Sinclair, S. (2001). Social influence effects on automatic racial prejudice. Journal of Personality and Social Psychology, 81, 842-855.

Mahan, J. (1976) Black and white children's racial identification and preference. Journal of Black Psychology, 3, 47-53.

Modood, T., Berthoud, R., Lakey, J., Nazroo, J., Smith, P., Virdee, S. \& Beishon, S. (1997). Ethnic Minorities in Britain: Diversity and Disadvantage. London: Policy Studies Institute. 
Nesdale, D. (1999a). Social identity and ethnic prejudice in children. In P. Martin \& W. Noble (Eds.), Psychology and Society (pp. 92-110). Brisbane, Australia: Australian Academic Press.

Nesdale, D. (1999b). Developmental changes in children's ethnic preferences and social cognitions. Journal of Applied Developmental Psychology, 20, 501-519.

Nesdale, D. (2001). The development of prejudice in children. In M. Augostinos \& K. Reynolds (Eds.). The Psychology of Prejudice and Racism (pp. 57-72). Thousand Oaks, CA: Sage.

Nesdale, D. (2004). Social identity and ethnic prejudice. In Bennett, M. \& Sani, F. (Eds.). The Development of the Social Self. East Sussex: Psychology Press.

Nesdale, D., Durkin, K., Maass, A., \& Griffiths, J. (2005a). Threat, group identification, and children's ethnic prejudice. Social Development, 14, 189-205.

Nesdale, D., Maass, A., Durkin, K., \& Griffiths, J. (2005b). Group norms, threat, and children's racial prejudice. Child Development, 76, 652-663.

Oakes, P. J., Haslam, S. A., \& Turner, J. C. (1994). Stereotyping and Social Reality. Oxford: Blackwell.

Ocampo, K., Knight, G., and Bernal, M. (1997). The development of cognitive abilities and social identities in children: the case of ethnic identity. International Journal of Behavioural Development, 21, 479-500.

Parekh, B. (2000). The Future of Multi-Ethnic Britain: The Parekh Report. London: The Runnymede Trust/Profile Books.

Powlishta, K. K. (1995). Gender bias in children's perceptions of personality traits. Sex Roles, $32,17-28$.

Pratto, F., Hegarty, P. J., \& Korchmaros, J. D. (in press). Who gets stereotyped? How communication practices and category norms lead people to stereotype particular people 
and groups. In Y. Kashima, K. Fielder, \& P. Freytag (Eds.), Dynamics: Language-based approaches to stereotype formation, maintenance and change. Mahwah, NJ: Erlbaum Publishers.

Pratto, F., Korchmaros, J. D., \& Hegarty, P. J. (in press). When race and gender go without saying. Manuscript submitted for publication.

Rutland, A., Cameron, L., Milne, A. \& McGeorge, P. (2005). Social norms and selfpresentation: Children's implicit and explicit intergroup attitudes. Child Development, $76,451-466$.

Semaj, L. (1980). The development of racial evaluations and preference: A cognitive approach. Journal of Black Psychology, 6, 2, 59-79.

Semaj L. (1985). Afrikanity, cognition and extended self-identity. In M. B. Spencer, G. K. Brookins, \& W. R. Allen (Eds.) Beginnings: Social and affective development of black children (pp 131-146). Hillsdale, NJ: Erlbaum.

Spencer, M. B. (1984). Black children's race awareness, racial attitudes and self-concept: A reinterpretation. Journal of Child Psychology and Psychiatry, 25, 433 - 441.

Spencer, M. B. (1985) Cultural Cognition and Social Cognition as Identity Correlates of Black Children's Personal-Social Development. In M. B. Spencer, G. K. Brookings \& W. R. Allen (Eds.) Beginnings: The Social and Affective development of Black Children Hillsdale, NJ: Erlbaum.

Spencer, M. B. (1988). Self-Concept Development in Black Children and Poverty: A Developmental perspective. New Directions for Child Development, 42 San Francisco: Jossey-Bass.

Spencer, M. B. (1990). Development of minority children: An introduction. Child Development, 61, 267-269. 
Spencer, M. B. \& Markstrom-Adams, C. M. (1990). Identity processes among racial and ethnic minority children in America. Child Development, 61, 290-310.

Tajfel, H. (1978). Differentiation between Social Groups: Studies in the Social Psychology of Intergroup Relations. London: Academic Press.

Tajfel, H., \& Turner, J. (1979). An integrative theory of intergroup conflict. In W. G. Austin \& S. Worschel (Eds.), The Social Psychology of Intergroup Relations (pp. 33-47). Pacific Grove, CA: Brooks/Cole Publishing.

Tajfel, H., \& Turner, J. (1986). The social identity of intergroup behaviour. In S. Worschel \& W.G. Austin (Eds.) The Psychology of intergroup relations (Vol. 2, pp7-24). New York: Nelson Hall.

Turner, J.C. (1999). Some current issues in research on social identity and self-categorization theories. In N. Ellemers, R. Spears \& B. Doosje (Eds.), Social Identity (pp. 6-34). Oxford: Blackwell.

Verkuyten, M. (2004). Ethnic identity and Social Context. In Bennett, M. \& Sani, F. (Eds.). The Development of the Social Self. East Sussex: Psychology Press.

Verkuyten, M. (2002). Ethnic attitudes among minority and majority children: The role of ethnic identification, peer group victimization and parents. Social Development, 11, $558-570$.

Verkuyten, M., \& Thijs, J. (2001). Ethnic and gender bias among Dutch and Turkish children in late childhood: The role of social context. Infant and Child Development, 10, 203217.

Wilson, T.D., Lindsey, S., \& Schooler, T.Y. (2000). A model of dual attitudes. Psychological Review, 107, 101-126.

Wilson, A. (1989). The Developmental Psychology of the Black Child. New York: Africana Research Publications. 
Yee, M. D. \& Brown, R. (1992) Self-evaluations and intergroup attitudes in children aged three to nine. Child Development, 63, 619-629. 
Table 1: Children's mean levels of positivity towards the black and the white targets in the explicit task by age (standard deviations in parentheses), and the results of associated one-sample $t$-tests.

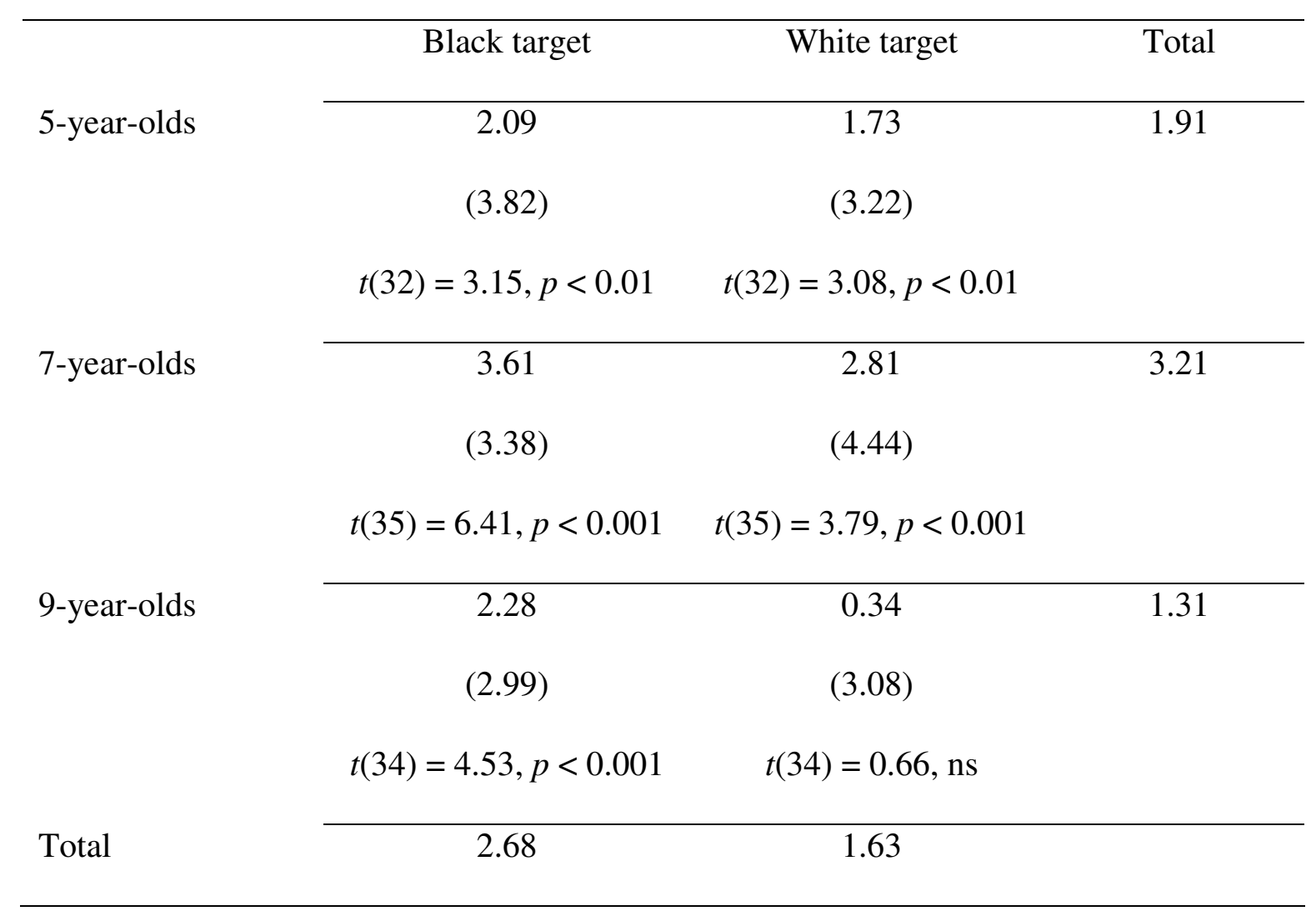


Table 2: Pearson partial correlations (with age partialled out) between intergroup attitude measures and strength of identification and self-esteem measures for black children.

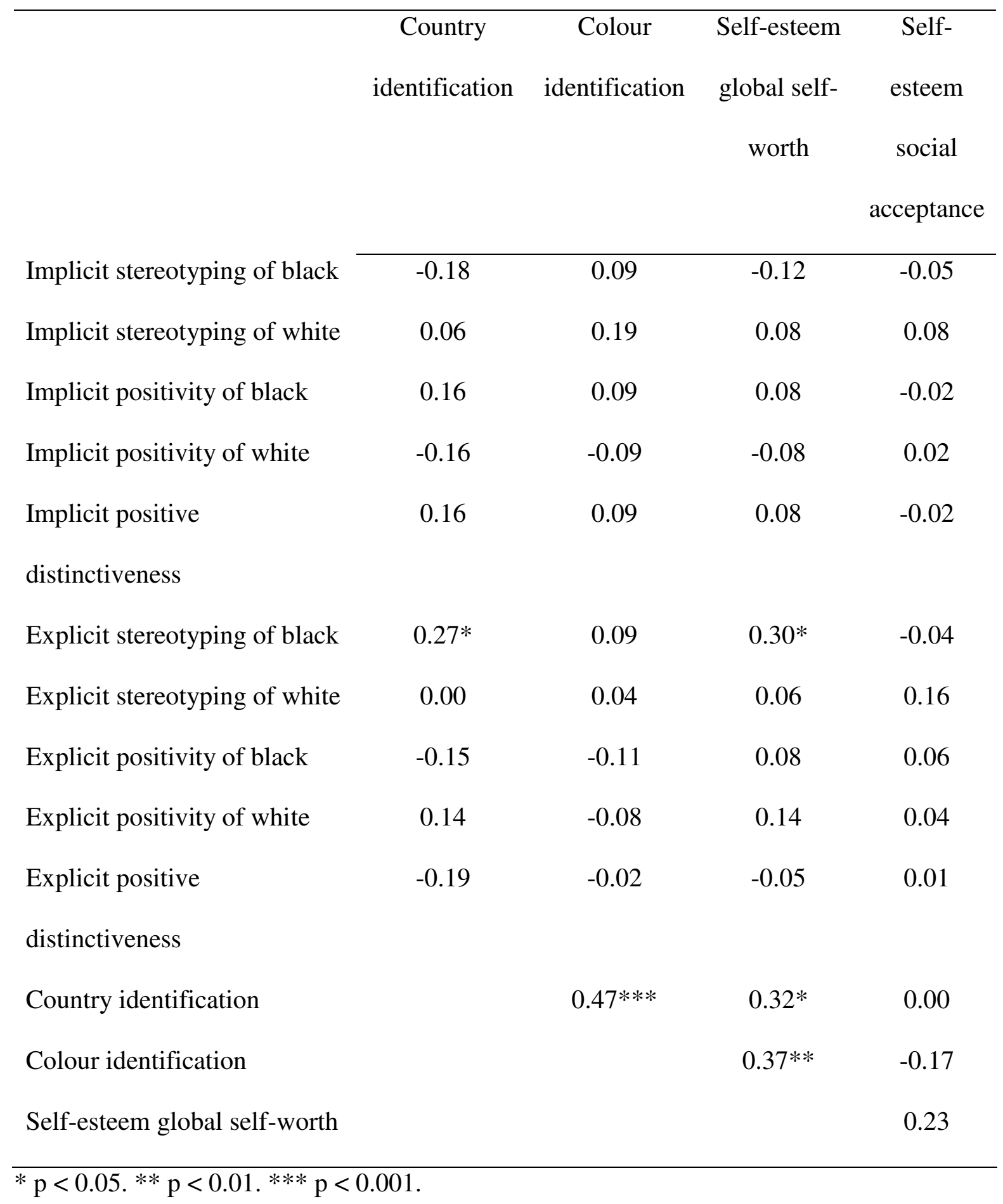


Table 3: Pearson partial correlations (with age partialled out) between intergroup attitude measures and strength of identification and self-esteem measures for white children.

\begin{tabular}{|c|c|c|c|}
\hline & $\begin{array}{c}\text { Country } \\
\text { identification }\end{array}$ & $\begin{array}{l}\text { Self-esteem } \\
\text { global self- } \\
\text { worth }\end{array}$ & $\begin{array}{l}\text { Self-esteem social } \\
\text { acceptance }\end{array}$ \\
\hline Implicit stereotyping of black & -0.25 & $-0.42 * *$ & -0.16 \\
\hline Implicit stereotyping of white & 0.01 & 0.08 & $0.32 *$ \\
\hline Implicit positivity of black & -0.02 & $-0.30^{*}$ & 0.00 \\
\hline Implicit positivity of white & 0.05 & $0.32 *$ & 0.00 \\
\hline $\begin{array}{l}\text { Implicit positive } \\
\text { distinctiveness }\end{array}$ & 0.04 & $0.31 *$ & 0.00 \\
\hline Explicit stereotyping of black & -0.05 & -0.14 & -0.06 \\
\hline Explicit stereotyping of white & 0.02 & 0.23 & -0.03 \\
\hline Explicit positivity of black & 0.08 & $-0.31 *$ & -0.09 \\
\hline Explicit positivity of white & 0.04 & 0.20 & 0.26 \\
\hline $\begin{array}{l}\text { Explicit positive } \\
\text { distinctiveness }\end{array}$ & -0.03 & $0.33 *$ & 0.23 \\
\hline Country identification & & 0.16 & -0.08 \\
\hline Self-esteem global self-worth & & & 0.17 \\
\hline
\end{tabular}


Table 4: Children's mean scores (Standard deviations in brackets) for individual traits on the Story Memory Task by Trait Stereotypicality, Trait Valence and Story Position.

\begin{tabular}{|c|c|c|c|c|c|c|}
\hline \multirow[t]{2}{*}{ Trait } & \multirow{2}{*}{$\begin{array}{l}\text { Trait Stereotypicality } \\
\text { (NS- Non-stereotypical; } \\
\text { S= Stereotypical) }\end{array}$} & \multirow{2}{*}{$\begin{array}{c}\text { Trait } \\
\text { Valence }\end{array}$} & \multirow{2}{*}{$\begin{array}{c}\text { Trait } \\
\text { Story } \\
\text { Position }\end{array}$} & \multicolumn{3}{|c|}{ Children's Mean score } \\
\hline & & & & Black & White & All \\
\hline Works hard & Black Non-stereotypical & Positive & 1 & $.84(.37)$ & $.84(.37)$ & $.84(.37)$ \\
\hline $\begin{array}{l}\text { Thinks s/he is } \\
\text { better than others }\end{array}$ & White stereotypical & Negative & 2 & $.49(.50)$ & $.59(.50)$ & $.53(.50)$ \\
\hline Stupid & White Non- stereotypical & Negative & 3 & $.91(.29)$ & $.93(.25)$ & $.92(.27)$ \\
\hline Likes doing things & Black Non- stereotypical & Positive & 4 & $.82(.38)$ & $.88(.32)$ & $.85(.36)$ \\
\hline with family & & & & & & \\
\hline $\begin{array}{l}\text { Likes doing things } \\
\text { alone }\end{array}$ & White stereotypical & Positive & 5 & $.82(.38)$ & $.86(.35)$ & $.84(.36)$ \\
\hline Rich & White non- stereotypical & Positive & 6 & $.68(.46)$ & $.63(.49)$ & $.66(.47)$ \\
\hline Greedy & Black non- stereotypical & Negative & 7 & $.52(.50)$ & $.66(.48)$ & $.58(.49)$ \\
\hline Dirty & White non- stereotypical & Negative & 8 & $.87(.33)$ & $.67(.48)$ & $.78(.41)$ \\
\hline Loud & Black stereotypical & Negative & 9 & $.52(.50)$ & $.77(.42)$ & $.63(.41)$ \\
\hline Good dancer & Black stereotypical & Positive & 10 & $.94(.22)$ & $.95(.21)$ & $.95(.22)$ \\
\hline Well-behaved & White stereotypical & Positive & 11 & $.54(.50)$ & $.82(.39)$ & $.66(.48)$ \\
\hline Ignores Others & White stereotypical & Negative & 12 & $.71(.45)$ & $.72(.45)$ & $.72(.46)$ \\
\hline Fast runner & Black stereotypical & Positive & 13 & $\begin{array}{l}1.00 \\
(.00)\end{array}$ & $.96(.21)$ & $.98(.14)$ \\
\hline Aggressive & Black stereotypical & Negative & 14 & $.72(.45)$ & $.68(.47)$ & $.70(.47)$ \\
\hline Polite & White non- stereotypical & Positive & 15 & $.48(.50)$ & $.68(.47)$ & $.57(.49)$ \\
\hline Smelly & Black non- stereotypical & Negative & 16 & $.67(.47)$ & $.80(.47)$ & $.72(.45)$ \\
\hline
\end{tabular}


